12 Chapman RM, Sutcliffe SB, Malpas JS. Cytotoxic induced ovarian failure in women with Hodgkin's disease. I: hormone function. FAMA 1979; 242: $1877-81$.

${ }^{13}$ Horning SJ, Hoppe RT, Caplan HS, Rosenberg SA. Female reproductive potential after treatment of Hodgkin's disease. $N$ Engl 7 Med 1981; 304:1377-82.

14 Schilsky RL, Sherins RF, Hubbard SN, Wesley MN, Young RC, de Vita VT. Long term follow up of ovarian function in women treated with MOPP chemotherapy for Hodgkin's disease. Am 7 Med 1981; 71:552-6.

15 Shamberger RC, Rosenberg SA, Seipp CA, Sherins RJ. Effects of high dose methotrexate and vincristine on ovarian and testicular function in patients undergoing postoperative adjuvant treatment of osteosarcoma. Cancer Treat Rep 1981;65:739-46.

${ }^{16}$ Warne G, Fairley KF, Hobbs JB, Martin FIR. Cyclophosphamide induced ovarian failure. $N$ Engl 7 Med 1973;289:1159-62.

${ }^{17}$ Fosdick WM, Parsons JL, Hill DF. Long term cyclophosphamide therapy in rheumatoid arthritis. Arthritis Rheum 1968;11:151-61.
${ }^{18}$ Bierman JM, Siegel E, French FE, Simonian K. Analysis of the outcome of all pregnancies in a community. Am 7 Obstet Gynecol 1965;91:37-45.

19 Stickle G. Defective development and reproductive wastage in the United States. Am $\mathcal{F}$ Obstet Gynecol 1968;100:442-7.

${ }^{20}$ Barber RK. Fetal and neonatal effects of cytotoxic agents. Obstet Gynecol $1981 ; 51: 415-75$.

${ }^{21}$ Holmes GE, Holmes FF. Pregnancy outcome of patients treated for Hodgkin's disease. A controlled study. Cancer 1978;41:1317-22.

22 McKeen EA, Mulvihill JJ, Rosner F, Zarrabi MH. Pregnancy outcome in Hodgkin's disease. Lancet 1979;ii:590.

${ }^{23} \mathrm{Li} \mathrm{FE}$, Fine W, Jaffe N, Holmes GE, Holmes FF. Offspring of patients treated for cancer in childhood. FNCI 1979;62:1193-97.

24 Ross GT. Congenital anomalies among children born of mothers receiving chemotherapy for gestational trophoblastic neoplasms. Cancer 1976; 37:1043-7.

${ }^{25}$ Bonadonna G. Chemotherapy strategies to improve the control of Hodgkin's disease. Cancer Res 1982;42:4309-20.

(Accepted 18 October 1983)

\title{
"Third drug" trial: comparative study of antihypertensive agents added to treatment when blood pressure remains uncontrolled by a beta blocker plus thiazide diuretic
}

\author{
D MCAREAVEY, L E RAMSEY, L LATHAM, A D MCLAREN, A R LORIMER, J L REID, \\ J I S ROBERTSON, M P ROBERTSON, R J WEIR
}

\begin{abstract}
Hydralazine, labetalol, methyldopa, minoxidil, prazosin, and placebo were compared when added by random allocation to atenolol $100 \mathrm{mg}$ and bendrofluazide $5 \mathrm{mg}$ daily in a series of 238 hypertensive patients inadequately controlled by the beta blocker-diuretic combination. Atenolol was withdrawn in those allocated to labetalol, and minoxidil was given only to men. The order of acceptability was: placebo, hydralazine, prazosin, methyldopa, minoxidil, labetalol. Minoxidil was more effective than the other active drugs, which had similar potency to one another. All the active agents were more effective than placebo.

Hydralazine was the most generally suitable third drug, with prazosin a close second. Minoxidil was especially effective in patients with less severe hypertension but the same regimen caused fluid retention in those with more severe disease. Labetalol should prob-
\end{abstract}

\footnotetext{
Glasgow Blood Pressure Clinics, Western Infirmary, Royal Infirmary, and Stobhill General Hospital, Glasgow

D MCAREAVEY, MD, MRCP, medical registrar

A R LORIMER, FRCP, consultant physician

J L REID, FRCP, professor of materia medica

J I S ROBERTSON, FRCP, FRSE, consultant physician

M P ROBERTSON, SRN, research assistant

R J WEIR, FRCP, consultant physician
}

University Department of Therapeutics, Royal Hallamshire Hospital, Sheffield

L E RAMSAY, MRCP, consultant physician

L LATHAM, SRN, research assistant

Department of Statistics, University of Glasgow, Glasgow G12 A D MCLAREN, MA, senior lecturer

Correspondence to: Dr J I S Robertson, MRC Blood Pressure Unit, Western Infirmary, Glasgow G11 6NT. ably be introduced at a low dose (150 $\mathrm{mg}$ daily) even when replacing full doses of a previously administered beta blocker.

\section{Introduction}

There is now much evidence that many of the complications of hypertension may be prevented by adequate control of the blood pressure. ${ }^{12}$ Recommended initial drug treatment is usually with a beta adrenergic blocking agent or thiazide diuretic. ${ }^{3}$ Where reduction of blood pressure is inadequate with a single drug the beta blocker and diuretic may be used together in a two drug regimen ${ }^{3}{ }^{4}$; some patients, however, may not achieve satisfactory control even with this combination of drugs, so that a third drug may be required. ${ }^{3}{ }^{4}$ Various different agents have been used in this role but there is only limited evidence to indicate which is most suitable. ${ }^{5}$

Among the drugs that may be added to a beta blockerdiuretic combination are methyldopa, hydralazine, prazosin, and minoxidil. Alternatively, labetalol (a combined alpha and beta blocker) may be substituted for a simple beta blocker. ${ }^{3}{ }^{4}$ Each of these drugs has been shown to have an additional hypotensive effect when given in such circumstances-for example, methyldopa, ${ }^{6}{ }^{7}$ hydralazine, ${ }^{8}{ }^{9}$ prazosin, ${ }^{81011}$ labetalol, ${ }^{12}{ }^{13}$ minoxidil. ${ }^{14} \mathrm{We}$, however, do not know of any controlled prospective study evaluating these "third step" drugs concurrently.

The following trial was therefore undertaken to compare both the efficacy and side effects of five different active drugs used as a third agent in patients whose blood pressure remained inadequately controlled by beta blocker and thiazide diuretic given together.

\section{Patients and methods}

Hypertensive patients aged 18-65 years were recruited from three blood pressure clinics in Glasgow (at the Royal Infirmary, Western Infirmary, and Stobhill General Hospital) and from the Royal 
Hallamshire Hospital, Sheffield. Ninety per cent of them had been treated with two or more drugs but blood pressure control remained unsatisfactory (greater than $140 \mathrm{~mm} \mathrm{Hg}$ systolic and $95 \mathrm{~mm} \mathrm{Hg}$ diastolic), and the remainder were severely hypertensive and had never been treated.

No patient included in the trial had severe or unstable angina and none had had a myocardial infarction within the previous three months. None had retinal haemorrhages, exudates, or papilloedema. Patients were also excluded if they had diabetes mellitus, past or present depression, anaemia, persistently deranged liver function values, serum creatinine concentration greater than $300 \mu \mathrm{mol} / 1$ $(3.4 \mathrm{mg} / 100 \mathrm{ml})$, residual severe disability after a stroke, a history of poor clinic attendance, evidence of poor compliance with treatment, or if they had had previous side effects from any of the trial drugs. No patient used any oestrogen-progestogen preparation during the trial. Each patient was supervised by a single physician throughout (Glasgow, DMcA; Sheffield, LER).

\section{MEASUREMENT OF BLOOD PRESSURE}

Blood pressure was measured by a single trained observer in each centre using a Hawksley random zero sphygmomanometer. ${ }^{15}$ Patients sat in the waiting room for at least 15 minutes after arriving at the clinic. Pulse rate was then checked and single measurements of blood pressure (using the same arm at each visit) made after lying for two minutes and standing for two minutes. Diastolic pressure was taken as the point of disappearance of sounds (phase V).

\section{RUN IN PERIOD}

Each patient considered for the study received a standard regimen of atenolol $100 \mathrm{mg} /$ day and bendrofluazide $5 \mathrm{mg} /$ day for a minimum of four weeks. During this time blood pressure was measured on two or more occasions, not less than one and not more than four weeks apart. Patients were withdrawn from the study if blood pressure fell to below $140 \mathrm{~mm} \mathrm{Hg}$ systolic and $95 \mathrm{~mm} \mathrm{Hg}$ diastolic. During the run in period investigations included chest radiography; electrocardiography; full blood count; measurement of serum urea, electrolyte, creatinine, cholesterol, and urate concentrations; liver function tests; random blood glucose measurement; and assay of serum antinuclear factor. At the end of the run in period patients whose systolic blood pressure had been $140 \mathrm{~mm} \mathrm{Hg}$ or more or diastolic pressure $95 \mathrm{~mm} \mathrm{Hg}$ or more on two consecutive visits were allocated at random to receive one of six additional drugs.

A total of 238 patients (mean age 53.5 (SD 9.4) years) qualified for reatment with a third drug. Of these, $156(75 \mathrm{men})$ were from Glasgow and $82(41 \mathrm{men})$ from Sheffield. Mean blood pressure of these 238 subjects had been 181/105 (SD 22/14) $\mathrm{mm} \mathrm{Hg}$ lying and $169 / 104(\mathrm{SD} 26 / 12) \mathrm{mm} \mathrm{Hg}$ standing on diverse regimens before the run in phase.

\section{RANDOMISATION}

Men were allocated at random to one of six drugs (hydralazine, labetalol, methyldopa, minoxidil, prazosin, or placebo) and women to one of five drugs (excluding minoxidil). Patients allocated to labetalol had the atenolol withdrawn. Randomisation schedules were balanced for each drug regimen separately for men and women and for each of the four participating hospitals.

Randomisation was aimed at (a) ensuring that only the statistician knew which treatment the next patient was to receive, until his or her randomisation envelope was opened; and $(b)$ allocating approximately equal numbers at each participating hospital to receive the various treatments. A schedule was drawn up as follows, independently for each of the four centres. In the interests of $(a)$ the precise method was known only to the statistician. Women were to receive one of five treatments. To achieve $(b)$ women were scheduled in groups of 10 , two in each group (selected with the aid of random number tables) to receive any particular treatment.

The schedules for men, some of whom were to receive a sixth treatment (minoxidil), were more complicated. Groups of 14 patients alternated with groups of seven patients (again in the interests of $(a)$ ). In the larger groups two patients (selected with the aid of random number tables) were to receive any particular treatment except minoxidil, which was given to four patients. In the smaller groups, of seven patients, minoxidil was given to two of them, and every other treatment to just one.

\section{TREATMENT REGIMENS}

The treatment regimens (table I) were agreed after consultation with the pharmaceutical company supplying the relevant drug. In the case of prazosin it is recommended that the initial dose should be taken at night so as to minimise acute postural hypotension. In order to standardise procedures the initial dose of the various other drugs was also taken on retiring at night. In general doses were increased at two weekly intervals (see table I). Increments in dose were continued until the target blood pressure was achieved, or until the scheduled maximum dose was reached, or until the dose was limited by side effects.

\section{END POINTS}

The target blood pressure was less than $140 \mathrm{~mm} \mathrm{Hg}$ systolic and less than $95 \mathrm{~mm} \mathrm{Hg}$ diastolic in recumbency. If target blood pressure was achieved on two consecutive visits patients continued with the same treatment and were reviewed every four weeks for six months. If target blood pressure was not achieved at two consecutive visits taking the top dose of the drug the patients ended the study. Patients were withdrawn if at any time blood pressure exceeded $240 \mathrm{~mm} \mathrm{Hg}$ systolic or $130 \mathrm{~mm} \mathrm{Hg}$ diastolic, if side effects were intolerable, if there was evidence of fluid retention (defined as weight gain of more than $2 \mathrm{~kg}$ with either development of peripheral oedema or dyspnoea), or if intercurrent disease precluded regular clinic attendance. If side effects prevented a further increment in drug dose but were not severe enough to require drug withdrawal patients ended the study after six weeks at the highest tolerated dose.

\section{SIDE EFFECTS}

Side effects were assessed in three ways. (a) Spontaneous comments by the patient were recorded at each clinic visit. (b) The doctor's inquiry about side effects was confined to a standard question, "Have the tablets agreed with you ?"; negative replies were investigated further and answers recorded. (c) Before randomisation and at the end of the study each patient completed a questionnaire on side effects based on that of Bulpitt and Dollery ${ }^{16}{ }^{17}$; questions included those about recognised drug side effects and invited free comment on treatment. The completed questionnaire was scrutinised and further details sought by the nurse or doctor if necessary.

TABLE I-Treatment regimens. (Tablet size indicated in parentheses)

\begin{tabular}{|c|c|c|c|c|c|c|}
\hline Increments & Methyldopa & Hydralazine & Prazosin & Labetalol & Minoxidil & Placebo \\
\hline $\begin{array}{l}\text { Initial evening dose } \\
\qquad \begin{array}{c}1 \\
2 \\
3 \\
4 \\
5\end{array}\end{array}$ & $\begin{array}{c}125 \mathrm{mg}(125 \mathrm{mg}) \\
125 \mathrm{mg} \text { twice daily } \\
\text { (125 mg) } \\
250 \mathrm{mg} \text { twice daily } \\
\text { (250 mg) } \\
500 \mathrm{mg} \text { twice daily } \\
\text { (250 mg) } \\
750 \mathrm{mg} \mathrm{twice} \mathrm{daily} \\
\begin{array}{c}\text { (250 mg) } \\
1000 \mathrm{mg} \text { twice daily } \\
(500 \mathrm{mg})\end{array}\end{array}$ & $\begin{array}{c}12.5 \mathrm{mg}(25 \mathrm{mg}) \\
12.5 \mathrm{mg} \text { twice daily } \\
\text { (25 mg) } \\
25 \mathrm{mg} \text { twice daily } \\
\text { (25 mg) } \\
50 \mathrm{mg} \mathrm{twice} \text { daily } \\
\text { (25 mg) } \\
75 \mathrm{mg} \mathrm{twice} \text { daily } \\
\text { (25 mg) } \\
100 \mathrm{mg} \text { twice daily } \\
\text { (50 mg) }\end{array}$ & $\begin{array}{c}0.5 \mathrm{mg}(1 \mathrm{mg}) \\
0.5 \mathrm{mg} \mathrm{twice} \text { daily } \\
\text { (1 mg) } \\
1 \mathrm{mg} \text { twice daily } \\
\text { ( } 1 \mathrm{mg}) \\
2 \mathrm{mg} \text { twice daily } \\
\text { (2 mg) } \\
5 \mathrm{mg} \text { twice daily } \\
\text { (5 mg) } \\
10 \mathrm{mg} \mathrm{twice} \mathrm{daily} \\
\text { (5 mg) }\end{array}$ & 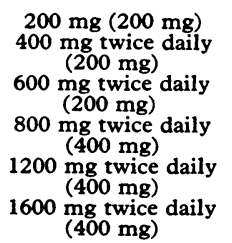 & $\begin{array}{c}2.5 \mathrm{mg}(5 \mathrm{mg}) \\
2.5 \mathrm{mg} \text { twice daily } \\
\text { (5 mg) } \\
5 \mathrm{mg} \text { twice daily } \\
\text { (5 mg) } \\
7.5 \mathrm{mg} \text { twice daily } \\
\text { (5 mg) } \\
10 \mathrm{mg} \text { twice daily } \\
\text { (5 mg) } \\
20 \mathrm{mg} \text { twice daily } \\
\text { (5 mg) }\end{array}$ & $\begin{array}{l}1 \text { capsule } \\
1 \text { capsule twice daily } \\
2 \text { capsules morning, } \\
1 \text { capsule evening } \\
2 \text { capsules twice daily } \\
3 \text { capsules morning, } \\
2 \text { capsules evening } \\
3 \text { capsules twice daily }\end{array}$ \\
\hline
\end{tabular}




\section{COMPLIANCE}

Compliance was assessed in two ways.

Tablet counts-At each clinic visit the patient was given a known but variable number of tablets and asked to return the unused tablets at the next outpatient session. Tablet counts were recorded.

Urinary drug assay-Urine samples were collected without warning at a clinic visit during the period of treatment with the third drug. Urine was deep frozen. Qualitative assay of urinary drug or metabolites or both was carried out, ${ }^{18-23}$ minoxidil being assayed by courtesy of Upjohn Ltd.

\section{ANALYSIS OF RESULTS}

Side effects were assessed $(a)$ by comparing the numbers of patients withdrawn from each drug regimen, $(b)$ by pairwise comparisons of reported and observed side effects, and (c) by analysis of the self administered questionnaire.

The hypotensive effect of the drug regimens was analysed, defining reduction in pressure as the difference between recordings made at the end of the run in period and those made either at the second visit taking the maximum dose of drug, if reached, or at the end of the study. Patients were excluded from this analysis if they had been withdrawn from the study because of side effects or for miscellaneous reasons or if they belonged to the placebo group from Sheffield in which the period of treatment was limited to six weeks.

At randomisation to the third drug average blood pressures were comparable in all treatment groups. Different numbers of subjects were withdrawn from the several groups during the trial, however, so that when the analysis was restricted to those patients completing the study average blood pressures at randomisation were not always comparable. As the hypotensive activity of many agents is proportional to the pretreatment blood pressure correction for differences in initial blood pressure was made in the analysis of results. Thus the hypotensive effect of the "third step" drugs was analysed by fitting linear regressions to relate reduction in pressure to the initial readings at randomisation.

\section{Results}

At the time of randomisation there were no significant differences in mean age or mean systolic or diastolic blood pressures among the groups. As randomisation was balanced the sex ratio for each treatment group was also similar with the exception of the group given minoxidil, which was used only in men (table II). Because the trial was halted before all the balanced randomisation schedules were complete the total number of patients taking any drug varied from 35 treated with minoxidil to 43 in the groups taking prazosin and placebo.

\section{SIDE EFFECTS}

\section{Severe side effects causing withdrawal from study}

Labetalol was responsible for more withdrawals than any other drug $(78 \% ; \mathrm{p}<0.05)$, the most frequent reasons being nausea, tiredness, aching limbs, and tingling of the skin. Of the total of 32 patients who could not tolerate labetalol, three withdrew within three days of starting the drug and a further five within two weeks.

Minoxidil was significantly better tolerated than labetalol but caused more withdrawals $(57 \% ; \mathbf{p}<0.05)$ than any of the remaining third step drugs. The main reason for withdrawal with minoxidil was fluid retention. Fluid retention was most pronounced in those with the most severe hypertension when minoxidil was introduced; by contrast, the drug was well tolerated in those with more mild hypertension. There were no significant differences in serum urea or creatinine concentrations between those patients taking minoxidil who continued to the end of the study and those who were withdrawn because of fluid retention.

There were no significant differences in withdrawal rates among methyldopa (33\% ; main reasons tiredness and nausea), prazosin $(21 \%$; tiredness and nausea), and hydralazine $(20 \%$; tiredness, headaches, nausea). Least troublesome was placebo, which only one patient could not tolerate, owing to loss of appetite and "dizziness."

\section{Less severe side effects reported and observed}

Significant differences in the frequency of complaints were found among the different regimens $(p<0.001)$, and the trends were apparent whether analysed as at randomisation to the third agent or as subgroups who continued in the study or were withdrawn because of side effects.

Significantly fewer symptoms were reported with placebo $(0.4$ per patient) than with any of the active drugs. The most frequent complaints with placebo, on a background of atenolol plus bendrofluazide, were mental and physical tiredness, "dizziness" (without demonstrable postural hypotension), and nausea.

Methyldopa was responsible for an average of $4 \cdot 1$ complaints per patient, in order of frequency being associated mainly with tiredness, "dizziness," nausea, dry mouth, and stuffy nose.

Labetolol was associated with 3.9 complaints per patient, predominantly "dizziness" (but without demonstrable postural hypotension), nausea, tiredness, aching limbs, tingling skin, and constipation.

Prazosin caused an average of 2.8 complaints per patient, the order of frequency being tiredness, "dizziness," dry mouth, constipation, and nausea. Prazosin was the only third step drug for which a significant orthostatic fall in blood pressure was apparent.

Minoxidil was accompanied by $2 \cdot 6$ complaints per patient, fluid retention in various manifestations being substantially the most frequent problem. Rarer symptoms with minoxidil were tiredness, "dizziness," constipation, and nausea.

Hydralazine gave 1.8 complaints per patient, tiredness and "dizziness" again being the most frequent. Other problems were headache, facial flushing, nausea, and constipation.

Of the active agents, methyldopa and labetalol caused significantly more problems than did prazosin and minoxidil, which in turn were significantly less well accepted than hydralazine.

\section{Side effects elicited by self administered questionnaire}

The self administered questionnaire appeared to be a less sensitive test of side effects than direct questioning by the doctor, probably because if offered a limited range of symptoms as set questions. Moreover, the pattern of side effects was rather different from that elicited by direct inquiry. There were no significant differences in side effects volunteered in the questionnaire among the groups before addition of the third drug, but the level of background complaints in these patients (all of whom were already receiving beta blocker plus diuretic) was high $(33 \%)$. After the addition of a third drug the only significant change was an increase in complaints of weakness of the limbs in patients taking labetalol $(p<0.05)$ and methyldopa $(p<0.05)$. By comparison with placebo labetalol also tended to cause increased complaints of nausea, vomiting, blurred vision, and headache. A trend to increased drowsiness and blurred vision was apparent with methyldopa. Prazosin caused a non-significant increase in weakness of the limbs.

No consistent effect on male sexual function was volunteered by

TABLE II-Comparability of drug groups at end of run in period. (Standard deviations in parentheses)

\begin{tabular}{|c|c|c|c|c|c|c|}
\hline & Hydralazine & Labetalol & Methyldopa & Minoxidil & Prazosin & Placebo \\
\hline $\begin{array}{l}\text { No of patients } \\
\text { M/F } \\
\text { Mean age (years) } \\
\begin{array}{r}\text { Mean systolic blood } \\
\text { pressure (mm Hg) }\end{array} \quad\left\{\begin{array}{l}\text { Lying } \\
\text { Standing }\end{array}\right.\end{array}$ & $\begin{array}{c}40 \\
16 / 24 \\
54 \cdot 3(9 \cdot 4) \\
171(17) \\
155(25)\end{array}$ & $\begin{array}{c}41 \\
16 / 25 \\
55 \cdot 0(6 \cdot 6) \\
171(19) \\
155(26)\end{array}$ & $\begin{array}{c}36 \\
14 / 22 \\
52 \cdot 8(8 \cdot 4) \\
179(23) \\
159(22)\end{array}$ & $\begin{array}{c}35 \\
35 / 0 \\
53 \cdot 5(9 \cdot 1) \\
167(20) \\
154(26)\end{array}$ & $\begin{array}{c}43 \\
18 / 25 \\
54 \cdot 6(8 \cdot 1) \\
181(24) \\
169(26)\end{array}$ & $\begin{array}{c}43 \\
17 / 26 \\
52 \cdot 2(10 \cdot 5) \\
167(16) \\
158(19)\end{array}$ \\
\hline$\underset{\text { pressure }(\mathrm{mm} \mathrm{Hg})}{\text { Mean diastolic blood }}\left\{\begin{array}{l}\text { Lying } \\
\text { Standing }\end{array}\right.$ & $\begin{array}{l}104(12) \\
107(13)\end{array}$ & $\begin{array}{l}98(13) \\
96(17)\end{array}$ & $\begin{array}{l}104(10) \\
103(12)\end{array}$ & $\begin{array}{r}101(12) \\
98(13)\end{array}$ & $\begin{array}{l}103(13) \\
103(13)\end{array}$ & $\begin{array}{r}99(10) \\
102(10)\end{array}$ \\
\hline
\end{tabular}


TABLE III-Mean blood pressures at time of randomisation and mean reductions in blood pressure achieved with the various drugs. Data on patients continuing to end of study only. Blood pressures in $\mathrm{mm} \mathrm{Hg}$. (Standard deviations in parentheses)

\begin{tabular}{|c|c|c|c|c|c|c|}
\hline & Hydralazine & Labetalol & Methyldopa & Minoxidil & Prazosin & Placebo \\
\hline $\begin{array}{l}\text { No of patients continuing in trial } \\
\text { M/F } \\
\text { Mean lying blood pressure at randomisation } \\
\text { Mean reduction in lying blood pressure } \\
\text { Mean standing blood pressure at randomisation } \\
\text { Mean reduction in standing blood pressure }\end{array}$ & $\begin{array}{c}28 \\
10 / 18 \\
170 / 103(18 / 11) \\
24 / 15(17 / 11) \\
157 / 101(25 / 13) \\
22 / 15(23 / 14)\end{array}$ & $\begin{array}{c}9 \\
4 / 5 \\
173 / 104(22 / 13) \\
25 / 11(20 / 12) \\
152 / 100(29 / 17) \\
29 / 15(26 / 17)\end{array}$ & $\begin{array}{c}18 \\
7 / 11 \\
184 / 103(25 / 11) \\
34 / 12(20 / 10) \\
165 / 102(25 / 10) \\
36 / 16(16 / 12)\end{array}$ & $\begin{array}{c}10 \\
10 / 0 \\
154 / 99(14 / 11) \\
26 / 16(18 / 9) \\
143 / 98(15 / 9) \\
22 / 14(23 / 12)\end{array}$ & $\begin{array}{c}29 \\
13 / 16 \\
183 / 105(25 / 15) \\
31 / 14(22 / 15) \\
169 / 103(29 / 14) \\
37 / 19(28 / 14)\end{array}$ & $\begin{array}{c}26 \\
10 / 16 \\
170 / 98(17 / 11) \\
9 / 5(17 / 12) \\
163 / 102(19 / 10) \\
10 / 6(20 / 14)\end{array}$ \\
\hline
\end{tabular}

patients taking active treatment when compared either with placebo or with the atenolol and bendrofluazide run in phase.

\section{CHANGES IN BLOOD PRESSURE}

The proportions of patients achieving the target blood pressure with the various drugs were as follows: hydralazine $25 \%$, minoxidil $23 \%$, prazosin $19 \%$, methyldopa $17 \%$, labetalol $9 \%$, placebo $0 \%$. Table III shows, for patients continuing to the end of the study, the mean blood pressure in each treatment group at time of randomisation to the third drug and the mean reduction in blood pressure eventually achieved.

The figure shows the regression lines for each drug, relating reduction in lying systolic blood pressure to initial blood pressure. In the minoxidil group patients with higher blood pressures at randomisation failed to complete the study and so are not included in this statistical analysis. Despite this limitation, minoxidil achieved significantly greater reduction in blood pressure than any of the other agents.

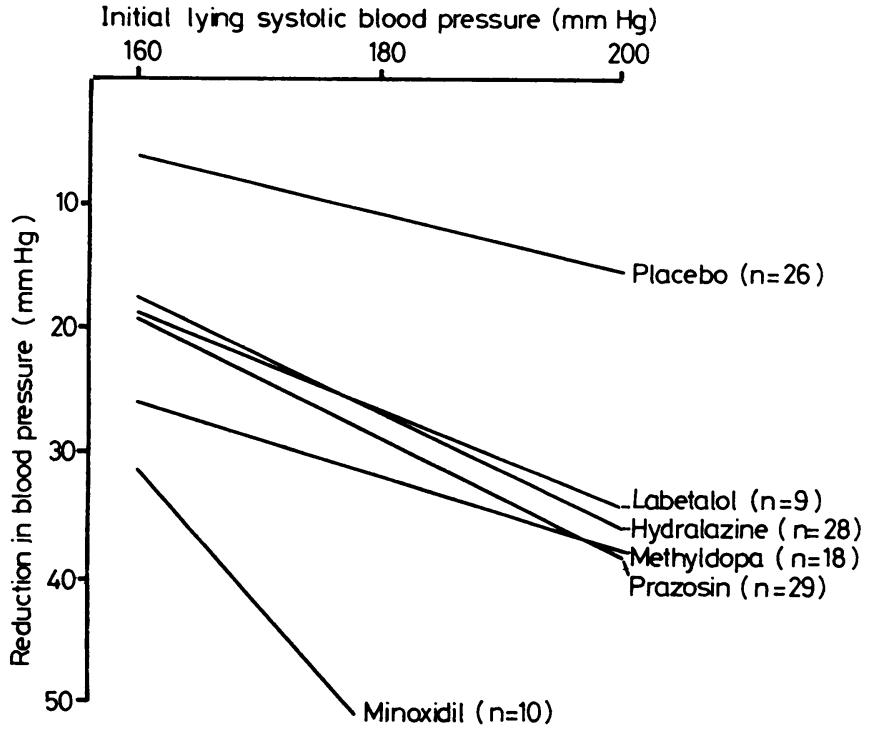

Regression lines relating reduction in blood pressure to initial lying systolic pressure for each drug group.

Placebo had significantly less hypotensive effect than any of the active drugs. No significant differences in hypotensive activity were apparent among methyldopa, prazosin, labetalol, and hydralazine. Similar results were obtained for lying diastolic blood pressure. Likewise, placebo had significantly less hypotensive effect on standing systolic and diastolic blood pressures than any other drug. No consistent differences in antihypertensive effect on standing could be detected among the five active agents.

These differences among the various drug groups, including the placebo group, held irrespective of whether the Glasgow and Sheffield data were analysed separately or were pooled. The differences between minoxidil and the other active agents were also still apparent when data were analysed using the subgroup of men only.

Before the addition of the third drug standing systolic pressure was significantly lower $(p<0.05)$ than lying systolic pressure for each drug group. There was also a trend for standing diastolic pressures to be lower than lying diastolic pressures but this was not significant. Prazosin was the only drug which significantly increased this postural fall in blood pressure $(p<0.05)$.

\section{COMPLIANCE}

Assessing compliance by tablet counts showed that $98 \%$ of patients had taken more than $80 \%$ of the tablets presented. Urinary drug assay from samples obtained on a single clinic visit showed that the third step drug or its metabolites were present in the urine sample in $\mathbf{7 4} \%$ of patients. The proportion of urine samples giving positive drug reactions ranged from $90 \%$ for the labetalol group to $56 \%$ in the methyldopa group. In $73 \%$ and $85 \%$ of samples respectively thiazide diuretic and atenolol were found.

\section{LABORATORY INVESTIGATIONS}

No significant changes in serum electrolyte, urate, creatinine, or urea concentrations or liver function values were observed during the study. Drug induced lupus was not observed and no significant changes in antinuclear factor were apparent among the drug groups. Haematological tests showed nothing unusual.

\section{SERIOUS INTERCURRENT DISEASE DURING STUDY}

Table IV summarises the serious events that occurred during the study. One man died after myocardial infarction. The patient taking prazosin who developed a stroke did not have previous postural hypotension.

TABLE IV-Occurrence of serious intercurrent disease during study

\begin{tabular}{|c|c|c|}
\hline Event & $\begin{array}{c}\text { No of } \\
\text { patients }\end{array}$ & $\begin{array}{c}\text { Random } \\
\text { drug }\end{array}$ \\
\hline Myocardial infarction & $\left\{\begin{array}{l}2^{*} \\
1\end{array}\right.$ & $\begin{array}{l}\text { Methyldopa } \\
\text { Minoxidil }\end{array}$ \\
\hline $\begin{array}{l}\text { Cerebrovascular accident } \\
\text { Prostatic neoplasm } \\
\text { Pelvic abscess } \\
\text { Thyrotoxicosis } \\
\text { Gout } \\
\text { Eczema-?thiazide related } \\
\text { Exacerbation of chronic bronchitis } \\
\text { Autoimmune haemolytic anaemia } \\
\text { Hepatitis }\end{array}$ & $\begin{array}{l}1 \\
1 \\
1 \\
1 \\
1 \\
1 \\
1 \\
1 \\
1 \\
1\end{array}$ & $\begin{array}{l}\text { Prazosin } \\
\text { Methyldopa } \\
\text { Prazosin } \\
\text { Prazosin } \\
\text { Prazosin } \\
\text { Minoxidil } \\
\text { Labetalol } † \\
\text { Methyldopa } \\
\text { Methyldopa } †\end{array}$ \\
\hline
\end{tabular}

* One died.

† Symptoms disappeared after drug withdrawal.

\section{Discussion}

Most patients with mild to moderate hypertension are said to respond satisfactorily to a beta adrenergic blocking agent or thiazide diuretic, given either alone or in combination. ${ }^{3-5}$ Atenolol was the beta blocker used in this study because of its long duration of action and relative cardioselectivity. ${ }^{24}$

There is little previous evidence on which to base the choice of a third drug to add to this combination if blood pressure remains high. In one retrospective study patients were not allocated at random to the trial drug, were not studied concurrently, and the duration of treatment varied. ${ }^{25}$ 
In our study the groups of patients were well matched in terms of age, arterial pressure at randomisation, and sex distribution. Blood pressures were measured with a random zero sphygmomanometer. In other respects, however, the trial was open; this is unlikely to have influenced withdrawals but might have affected the pattern of reported side effects.

We do not think that poor patient compliance could have confounded the results of this study. Patients were selected on the basis of reliability and compliance as assessed subjectively by clinic doctors and nurses. The achievement of satisfactory compliance was supported by tablet counts. In $98 \%$ of cases at least $80 \%$ of tablets prescribed had been consumed or, at any rate, were not returned at the next visit. Drug detection in urine further indicated a high compliance rate. There were only a few occasions when assessment by tablet count did not correlate with the results of drug assay; in the main these two measures of compliance corresponded. The occasional lack of correspondence probably reflected inadequacies in both methods of assessment. There is still no simple measure of compliance which can be applied to long term drug treatment to give absolute confirmation that the patient has responded to medical instruction on all occasions.

Some pronounced differences were found between the various third step agents evaluated. All the active drugs lowered blood pressure more than did placebo. Minoxidil was more potent than all the other agents, which in turn were similar to one another in efficacy, a result in agreement with previous reports. ${ }^{26} 27 \mathrm{On}$ this background of atenolol and bendrofluazide only prazosin was seen to have a distinct postural enhancement of effect.

The drug groups were more clearly differentiated according to their acceptability to the patient. All active drugs caused significantly more side effects than did placebo. Labetalol caused more patients to withdraw from treatment than did all the other drugs, and minoxidil significantly more than all the remainder. Of the active agents, fewest withdrawals were seen with prazosin and hydralazine, with methyldopa placed intermediately between prazosin and minoxidil.

Assessment of less severe side effects permitted further discrimination. Hydralazine was overall the most acceptable active drug, being marginally superior to prazosin. This contrasts with an earlier report ${ }^{8}$ in which prazosin caused fewer side effects than hydralazine. Our trial was of limited duration, however, and it is possible that had the study continued longer some instances of hydralazine induced lupus might have appeared, as described in other clinics. ${ }^{28}$ Methyldopa was significantly less acceptable than either prazosin or hydralazine.

The pattern of side effects was not unexpected. The most frequent complaints were of tiredness and "dizziness." As these were found also in the placebo group they might well have resulted from the background treatment with atenolol and bendrofluazide. These symptoms apart, predominant complaints were of headache with hydralazine; dry mouth with prazosin; nausea and dry mouth with methyldopa; oedema with minoxidil; and nausea, vomiting, and formication with labetalol.

Minoxidil caused the most pronounced fluid retention in those patients most severely hypertensive when it was introduced; the drug was well tolerated and very effective in more mildly hypertensive patients. These differences could not be explained by differences in renal function at the outset. Although minoxidil appears only rarely to have been employed together with a thiazide diuretic, ${ }^{27}$ this combination seems to be effective and well tolerated in less severely hypertensive patients. ${ }^{27} \mathrm{~A}$ loop diuretic, however, is clearly more appropriate for use with minoxidil than is thiazide in severe resistant hypertension. ${ }^{4} 142529$

Probably the problems encountered with labetalol resulted mainly from its introduction at substantial doses $(400 \mathrm{mg}$ twice daily) immediately on discontinuing atenolol. We considered the possibility that the particularly high incidence of side effects with labetalol was a result of its being absorbed before atenolol had fully cleared from the body. If this were so most of the withdrawals from this group should have been seen shortly after starting the drug. Twenty four patients, however, continued with labetalol for more than two weeks before finding symptoms intolerable. The dosage increments of labetalol that we used were at the beginning of the trial thought to be appropriate as replacement for the full doses of atenolol already being given, but the results of the trial showed clearly that they were not. Takeda et al emphasised that labetalol is well tolerated if dosage is built up gradually from $150 \mathrm{mg}$ daily. ${ }^{30}$ Thus labetalol may be useful as a "third step" drug if the dose is more gradually titrated. This possibility needs to be evaluated using a different dose schedule from that in this study.

In conclusion, therefore, all of the five active drugs considered in this trial were more effective in lowering blood pressure than was placebo, but each caused more side effects than did placebo. The large number of side effects encountered with labetalol may be partly explained by its introduction in substantial dose. Minoxidil appeared to be effective and safe in combination with bendrofluazide in moderately hypertensive patients; however, loop diuretics are required in combination with this potent vasodilator for more severe hypertension. Methyldopa was only modestly well tolerated with a substantial number of subjective side effects and with two serious adverse reactions (hepatitis and autoimmune haemolytic anaemia). Thus the most generally suitable drugs to add to a beta blocker-diuretic combination are hydralazine and prazosin. Prazosin is slightly less satisfactory in terms of frequency of side effects and also causes mild orthostatic hypotension.

Use of these various agents as third step drugs in the present context does not imply that their value in the treatment of hypertension is restricted to such a role.

We are grateful to Ciba-Geigy, Glaxo, ICI Pharmaceuticals, Merck, Sharp and Dohme, Pfizer, and Upjohn for financial support and advice. We also thank Dr James Bunney, of the department of pharmacy, Stobhill General Hospital, Glasgow, for invaluable help.

\section{References}

1 Veterans Administration Cooperative Study Group on Antihypertensive Agents. Effects of treatment on morbidity in hypertension. II. Results in patients with diastolic blood pressures averaging 90 through $114 \mathrm{~mm} \mathrm{Hg}$. $\mathcal{F} A M A$ 1970;213:1143-52.

${ }^{2}$ Australian Therapeutic Trial in Mild Hypertension. Lancet 1980;i:1261-7.

3 Arterial Hypertension. Report of a WHO expert committee. WHO Tech Rep Ser 1978; No 628.

${ }^{4}$ Mackay A, Isles C, Atkinson AB, et al. The treatment of resistant hypertension. In: Jewell DP, ed. Advanced medicine. Vol 17. London: Royal College of Physicians of London/Pitman Medical, $1981: 39-58$.

${ }^{5}$ Ramsay LE. Diuretic and beta-blocker in hypertension-then what ? $\mathcal{F} R$ Coll Physicians Lond 1980;14:249-53.

6 Petrie JC, Galloway DB, Jeffers TA, et al. Methyldopa and propranolol or practolol in moderate hypertension. $\mathrm{Br}$ Med $\mathcal{F}$ 1976;ii:137-9.

7 Webster J, Jeffers TA, Galloway DB, Petrie JC, Barker NP. Atenolol, methyldopa, and chlorthalidone in moderate hypertension. $\mathrm{Br} \mathrm{Med} \mathscr{f}$ $1977 ; \mathrm{i}: 76-8$.

${ }^{8}$ Kincaid-Smith P, Hua ASP, Myers JP, Macdonald I, Fang P. Prazosin and hydrallazine in the treatment of hypertension. Clinical Science and Molecular Medicine 1976;51:617-9s.

9 Wilcox RG, Mitchell JRA. Contribution of atenolol, bendrofluazide and hydrallazine to management of severe hypertension. $\mathrm{Br} \mathrm{Med} \mathcal{F} 1977$;ii: 547-50.

10 Stokes GS, Weber MA. Prazosin: preliminary report and comparative studies with other antihypertensive agents. Br Med f 1974;ii :298-300.

1 Hua A, Macdonald JM, Myers JP, Kincaid-Smith P. Studies with prazosin-a new hypotensive agent. I. Open clinical study of prazosin in combination with other antihypertensive agents. Med $\mathcal{F}$ Aust 1976;i: 559-61.

12 Prichard BNC, Boakes AJ. Labetalol in long-term treatment of hypertension. Br f Clin Pharmacol 1976;3:743-50.

13 Prichard BNC, Richards DA. Comparison of labetalol with other antihypertensive drugs. Br f Clin Pharmacol 1982;13, suppl 1:41-7s.

14 Devine B, Fife R, Trust PM. Minoxidil for severe hypertension after failure of other hypotensive drugs. $B r$ Med 7 1977;ii:667-9.

15 Wright BM, Dore CF. A random zero sphygmomanometer. Lancet 1970; i:337-8.

${ }^{16}$ Bulpitt CJ, Dollery CT. Side-effects of hypotensive agents evaluated by a self-administered questionnaire. $\mathrm{Br}$ Med f 1973;iii:485-90.

17 Bulpitt CJ, Dollery CT, Carne S. A symptom questionnaire for hypertensive patients. $\mathcal{f}$ Chronic Dis $1974 ; 27: 309-23$. 
18 Yee Y, Rubin PC, Blaschke T. Determination by HPLC and fluorescence detection. F Chromatogr 1979;171:357-62.

10 Tisdall PA, Meyer TP, Anhalt JP. Liquid chromatographic detection of thiazide diuretic in urine. Clin Chem $1980 ; 26: 702-6$

${ }^{20}$ Meredith PA, McSharry DR, Elliott HL, Reid JL. The determination of labetalol in plasma by HPLC using fluorescence detection. $\mathcal{F}$ Pharmacol Methods $1981 ; 6: 309-14$.

21 Yee Y, Rubin PC, Meffin P. Prazosin determination by HPLC using fluorescence detection. $\mathcal{f}$ Chromatogr 1979;172:313-8.

${ }^{22}$ Moyer P, Jiang NS, Tyce GM, Sheps SG. Analysis for urinary catecholamines by high chromatography with amperometric detection. Clin Chem $1979 ; 25: 256-63$.

${ }^{23}$ Reece PA, Cozamaris I, Zacest R. Selective HPLC assays for hydralazine and its metabolites in plasma of man. $\mathcal{F}$ Chromatogr $1980 ; 181: 427-40$

${ }^{24}$ Robertson JIS, Kaplan NM, Caldwell ADS, Speight TM. Beta-blockade in the nineteen-eighties: focus on atenolol. Drugs $1983 ; 25$, suppl 2 : $1-346$.
25 Swales JD, Bing RF, Heagerty A, Pohl JEF, Russell GI, Thurston H. Treatment of refractory hypertension. Lancet 1982 ;i:894-6.

26 Connor G, Wilburn RL, Bennett CM. Double-blind comparison of minoxidil and hydrallazine in severe hypertension. Clinical Science and Molecular Medicine 1976;51:593-55.

27 Johnson BF, Black HR, Beckner R, Weiner B, Angeletti F. A comparison of minoxidil and hydralazine in non-azotemic hypertensives. Fournal of Hypertension 1983; :103-7.

28 Bing RF, Russell GI, Thurston H, Swales JD. Hydrallazine in hypertension: is there a safe dose ? $B r M e d f 1980 ; 281: 353-4$.

29 Mackay A, Isles C, Henderson I, Fife R, Kennedy AC. Minoxidil in the management of intractable hypertension. $Q \mathcal{F}$ Med $1981 ; 50: 175-90$.

30 Takeda T, Kaneko Y, Omae T, et al. The use of labetalol in Japan: results of multi-centre clinical trials. Br $\mathcal{f C l i n}$ Pharmacol $1982 ; 13$, suppl $1: 49-58 \mathrm{~s}$

(Accepted 18 October 1983)

\section{SHORT REPORTS}

\section{Widespread bone infarction complicating meningococcal septicaemia and disseminated intravascular coagulation}

Fulminant meningococcal septicaemia is often accompanied by disseminated intravascular coagulation, which may cause widespread skin necrosis and infarction of organs such as the adrenals, brain, and kidneys. ${ }^{1}$ We describe a patient who developed extensive bone infarction after meningococcal septicaemia.

\section{Case report}

A 19 year old West Indian man was unwell for 12 hours and was admitted to hospital when he became unrousable. He was deeply unconscious, had pronounced neck stiffness, and developed an ecchymotic rash that spread rapidly. His temperature was $37 \cdot 1^{\circ} \mathrm{C}$ and blood pressure $90 / 0 \mathrm{~mm} \mathrm{Hg}$. Fulminant meningococcal septicaemia with meningitis was diagnosed; there were Gram negative diplococci in the cerebrospinal fluid and Neisseria meningitidis, group $W 135$, was cultured from blood and cerebrospinal fluid. He showed evidence of disseminated intravascular coagulation with a low platelet count $\left(48 \times 10^{9} / 1\right)$, increased fibrin degradation products $(128 \mu \mathrm{g} /$ $\mathrm{ml}$, normal 0-8 $\mu \mathrm{g} / \mathrm{ml}$ ), prothrombin time (34 $\mathrm{s}$, control $14 \mathrm{~s}$ ), and kaolin

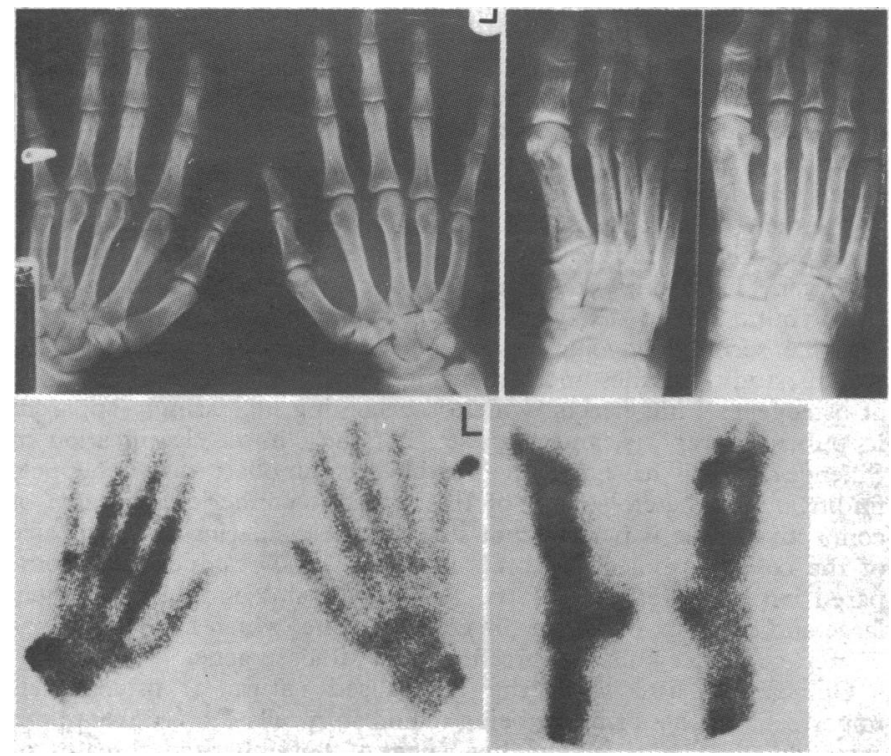

$X$ ray films and isotope bone scans of our patient's hands and feet three weeks after admission showing widespread, patchy osteolysis, periosteal reaction, and abnormal isotope uptake. cephalin clotting time (62 s, control $40 \mathrm{~s}$ ). A test for haemoglobin $\mathrm{S}$ yielded a negative result, and haemoglobin electrophoresis was normal. He was immediately given intravenous benzylpenicillin 4 MU every four hours and a single dose of hydrocortisone $200 \mathrm{mg}$. He improved rapidly and hydrocortisone was discontinued. Heparin was not given. Within 24 hours he was fully orientated, and the laboratory evidence of disseminated intravascular coagulation resolved over the next four days. The ecchymotic lesions became necrotic and healed slowly after débridement of extensive slough. He developed dry gangrene of three left toes, necessitating amputation of the distal phalanges.

His temperature did not respond, remaining at $38.5^{\circ} \mathrm{C}$ despite three weeks' treatment with penicillin. He felt well and had no localising signs of infection or evidence of arthritis or endocarditis. Cerebral abscess and subdural collection were excluded by computed tomography of the brain. There was no leucocytosis, and repeated cultures of blood, urine, and skin swabs were negative.

Eleven days after admission a radiograph of his left foot showed widespread cortical bone destruction and periosteal reaction (figure) not typical of osteomyelitis. There were similar radiographic changes in the right foot, both hands (figure), and both tibias, fibulas, radiuses, and ulnas. A ${ }^{99} \mathrm{~m} T$ diphosphonate bone scan showed areas of increased isotope uptake corresponding to the abnormal areas on the $x$ ray film (figure). Antibiotics were stopped after three weeks and the fever resolved 44 days after admission. Apart from the fever and muscle wasting he showed no clinical manifestations of bone disease. Further $x$ ray examinations after six weeks showed partial resolution of the abnormalities. Serum calcium and phosphate concentrations and serum alkaline phosphatase activity were normal throughout.

\section{Comment}

The radiographic and bone scan appearances suggested widespread bone infarction caused by intravascular deposition of fibrin during the episode of disseminated intravascular coagulation. ${ }^{1}$ The pattern of the bone changes, often with both sides of a joint being affected, the absence of local infection and leucocytosis, the patient's good health, the negative blood cultures, and the failure to respond to high doses of penicillin all argued against the diagnosis of-osteomyelitis. Other causes of bone necrosis such as sickle cell disease and high dose steroid treatment could also be discounted. We have found only one previous report of this phenomenon, that of a 2 year old boy who showed similar radiographic changes after meningococcal septicaemia with disseminated intravascular coagulation. ${ }^{2}$ Abnormal bone growth, epiphyseal destruction, and premature epiphyseal-metaphyseal fusion have also been described as late consequences of meningococcal sepsis in eight children, ${ }^{3}$ and these changes may be late sequelae of bone infarction. Acute bone changes similar to those in our patient have also been observed in a 10 day old boy with klebsiella septicaemia and disseminated intravascular coagulation. ${ }^{4}$

Apart from pyrexia the bone necrosis in our patient was clinically silent; the late consequences seen in children probably could not occur in an adult whose growth is complete. Bone necrosis should be considered among the possible causes of persistent fever after meningococcal septicaemia. The radiological changes (figure) may be mistaken for those of osteomyelitis if they are found in a single bone. $X$ ray examinations of other bones and an isotope bone scan may suggest the correct diagnosis. 